\title{
Gibberellin-Abscisic Acid Balances during Arbuscular Mycorrhiza Formation in Tomato
}

\author{
José A. Martín-Rodríguez', Raúl Huertas ${ }^{1}$, Tania Ho-Plágaro', Juan A. Ocampo', \\ Veronika Turečková2, Danuše Tarkowská ${ }^{2}$, Jutta Ludwig-Müller ${ }^{3}$ and \\ José M. García-Garrido ${ }^{*}$ \\ ' Department of Soil Microbiology and Symbiotic Systems, Estación Experimental del Zaidín, Consejo Superior de \\ Investigaciones Cientificas, Granada, Spain, ${ }^{2}$ Laboratory of Growth Regulators, Centre of the Region Haná for \\ Biotechnological and Agricultural Research, Institute of Experimental Botany, Academy of Sciences of the Czech Republic, \\ v.v.i., Palacký University, Olomouc, Czech Republic, ${ }^{3}$ Institut für Botanik, Technische Universität Dresden, Dresden, Germany
}

OPEN ACCESS

Edited by: Andrea Genre,

University of Turin, Italy

Reviewed by:

Ulrike Mathesius,

Australian National University,

Australia

Raffaella Balestrini,

National Research Council, Italy

*Correspondence:

José M. García-Garrido

josemanuel.garcia@eez.csic.es

Specialty section:

This article was submitted to

Plant Biotic Interactions,

a section of the journal

Frontiers in Plant Science

Received: 01 June 2016

Accepted: 10 August 2016

Published: 23 August 2016

Citation:

Martín-Rodríguez JA, Huertas $R$,

Ho-Plágaro T, Ocampo JA,

Turečková V, Tarkowská $D$,

Ludwig-Müller $J$ and

García-Garrido JM (2016)

Gibberellin-Abscisic Acid Balances

during Arbuscular Mycorrhiza

Formation in Tomato.

Front. Plant Sci. 7:1273.

doi: 10.3389/fpls.2016.01273
Plant hormones have become appropriate candidates for driving functional plant mycorrhization programs, including the processes that regulate the formation of arbuscules in arbuscular mycorrhizal (AM) symbiosis. Here, we examine the role played by ABA/GA interactions regulating the formation of $A M$ in tomato. We report differences in $\mathrm{ABA}$ and GA metabolism between control and mycorrhizal roots. Active synthesis and catabolism of ABA occur in AM roots. GAs level increases as a consequence of a symbiosis-induced mechanism that requires functional arbuscules which in turn is dependent on a functional ABA pathway. A negative interaction in their metabolism has been demonstrated. ABA attenuates GA-biosynthetic and increases GA-catabolic gene expression leading to a reduction in bioactive GAs. Vice versa, GA activated ABA catabolism mainly in mycorrhizal roots. The negative impact of $\mathrm{GA}_{3}$ on arbuscule abundance in wild-type plants is partially offset by treatment with ABA and the application of a GA biosynthesis inhibitor rescued the arbuscule abundance in the ABA-deficient sitiens mutant. These findings, coupled with the evidence that ABA application leads to reduce bioactive $\mathrm{GA}_{1}$, support the hypothesis that ABA could act modifying bioactive GA level to regulate AM. Taken together, our results suggest that these hormones perform essential functions and antagonize each other by oppositely regulating $\mathrm{AM}$ formation in tomato roots.

Keywords: arbuscular mycorrhiza, plant hormones, gibberellins, abscisic acid, symbiosis, tomato

\section{INTRODUCTION}

Several studies have shown that ABA and GAs, whose optimal balance is essential for normal plant development, interact antagonistically in numerous plant developmental processes (Weiss and Ori, 2007; Rodríguez-Gacio et al., 2009). ABA is a positive regulator of dormancy induction and its maintenance. On the other hand, while it is a negative regulator of germination, GAs release

Abbreviations: ABA, abscisic acid; ABA-GE, ABA-glucosyl ester; AM, arbuscular mycorrhiza; CPS, ent-copalyl diphosphate synthase; CYP, cytochrome P450; DPA, dihydrophaseic acid; GA, gibberellin; GAox, gibberellin oxidase; NCED, 9-cis-epoxycarotenoid dioxygenase; PA, phaseic acid; PrCa, prohexadione-calcium; qRT-PCR, quantitative RT-PCR; UPLC-ESI(+)MS/MS, ultra performance liquid chromatography-electrospray ionization-tandem mass spectrometry. 
dormancy, promote germination and counteract the impact of ABA (Kucera et al., 2005). In citrus fruits, ABA increased and $\mathrm{GA}_{20}$ decreased under water stress conditions, whereas rehydration reduced $\mathrm{ABA}$ but increased $\mathrm{GA}_{20}$ (Mahouachi et al., 2005). In mature embryos, the inhibition of GA synthesis mimicked the effects of exogenous ABA by suppressing germination, acquiring anthocyanin pigments and by accumulating a variety of maturation-phase mRNAs (White et al., 2000). ABA and GAs also antagonistically regulate their own metabolic processes. Thus, low ABA level promotes GA biosynthesis (Seo et al., 2006) and vice versa (Oh et al., 2007). However, the precise molecular mechanism underlying $\mathrm{ABA}$ and GA antagonism is still unknown. A recent study points out that ABA-INSENSITIVE 4 (ABI4) is a central factor in GA/ABA homeostasis and suggests that ABA and GA antagonize each other by oppositely acting on ABI4 transcript and protein levels (Shu et al., 2016).

This antagonistic interaction between ABA and GAs could apply to their role in AM regulation. The AM is the most widespread mutualistic association in the plant kingdom. The efficiency of the symbiosis is mainly due to the development of an extensive and branched fungal hyphal network outside the roots that efficiently uptakes mineral nutrients (principally phosphorous) which are transferred to plant cortical cells by specialized intraradical, highly branched structures named arbuscules. In return the plant provides the fungus with carbon (Smith and Read, 2008). Fungal penetration and establishment in roots depend on a complex sequence of events and intracellular modifications that are dynamically regulated by the plant, probably according their physiological and developmental status that result from environmental conditions (Pozo et al., 2015).

Previous studies indicate that plant hormones become appropriate candidates for driving functional plant mycorrhization programs (Bonfante and Genre, 2010; LudwigMüller, 2010; Floss et al., 2013; Gutjahr, 2014). ABA is a sesquiterpenoid hormone, derived from carotenoids, which functions at multiple levels to regulate $\mathrm{AM}$ symbiosis. In this way in many plant species it has been observed as the concentration of ABA rises during the establishment of mycorrhization (Ludwig-Müller, 2010). Recent studies suggest a dose-dependent effect of ABA modulating the establishment of AM symbiosis in Medicago truncatula by promoting fungal colonization at low concentrations and its impairment at high concentrations (Charpentier et al., 2014). In tomato, the analysis of AM colonization in the ABA-deficient tomato mutant sitiens, deficient in functional enzyme activity at the final step in ABA biosynthesis, has demonstrated that $\mathrm{ABA}$ plays an important role in the development and functionality of arbuscules (HerreraMedina et al., 2007; Martín-Rodríguez et al., 2010). In addition, ABA deficiency also results in the induction of ethylene production, which adversely affects mycorrhizal intensity (Herrera-Medina et al., 2007; Martín-Rodríguez et al., 2010, 2011). In addition, variations in the mycorrhization characteristics of wild-type and ABA-deficient tomato roots are accompanied by specific transcriptomic alterations associated with differences in the status of mycorrhization according to ABA content in roots (García-Garrido et al., 2010).

An opposite trend can be observed following the application of gibberellic acid $\left(\mathrm{GA}_{3}\right)$, with a dose-dependent suppression of arbuscule formation being reported in plants treated with GA $_{3}$ (El Ghachtouli et al., 1996; Foo et al., 2013; MartínRodríguez et al., 2015). Gibberellins are synthesized from carotenoid precursors by the action of GA 20-oxidases and $3 \beta$-hydroxylases. Several GA biosynthetic pathways with different hydroxylation patterns have been detected in various plant species (Hedden and Thomas, 2012), and GAs from the 13hydroxylation biosynthetic pathway have been shown to be significantly more abundant in the roots of AM inoculated plants than in those of non-mycorrhizal plants (Shaul-Keinan et al., 2002; Martín-Rodríguez et al., 2015), while, in tomato, the higher levels of GAs in mycorrhizal roots correlate closely with increased gene expression associated with GA biosynthesis (MartínRodríguez et al., 2015). Furthermore, arbuscule formation is regulated by DELLA proteins in M. truncatula (Floss et al., 2013), rice (Yu et al., 2014), and pea (Foo et al., 2013). DELLA proteins are nuclear proteins that negatively regulate GA signaling. Conversely, GAs offset the effects of DELLA proteins by promoting DELLA protein destabilization (Silverstone et al., 2001). It has been suggested that DELLA is a positive regulator of arbuscule formation and also acts as a core connecting different signaling pathways activated during AM formation (Floss et al., 2013; Yu et al., 2014; Pimprikar et al., 2016).

Abscisic acid treatment has been shown to stabilize DELLA proteins in the presence of GAs (Achard et al., 2006), and both DELLA proteins and ABA act as positive regulators of arbuscule formation (reviewed by Gutjahr, 2014). The control of GA levels through a combination of biosynthesis and degradation in mycorrhizal roots could therefore partly depend on ABA, even more so when ABA and GAs antagonistically regulate their own metabolic processes (Seo et al., 2006; Oh et al., 2007). In this study, we have aimed to analyze the role played by ABA/GA imbalance regulating the formation of $\mathrm{AM}$ symbiosis in tomato plants. Using a combination of hormone analysis, gene expression, and application studies we demonstrate the antagonistic effects of both plant hormones on arbuscule abundance in roots. Being as ABA interacts with the expression pattern of metabolism-related GA genes in mycorrhizal plants, and the AM phenotype of low ABA mutant sitiens can be improved by GA biosynthesis inhibitor, we postulated that ABA may act in part via modifying bioactive GA level to regulate AM. Furthermore, an antagonistic effect of $\mathrm{GA}_{3}$ applications on endogenous ABA accumulation was observed, suggesting that the imbalance in the ABA/GA ratio is capable of reducing arbuscule abundance in these mutants. We therefore conclude that the balance between ABA and GAs is essential for AM formation in tomato roots. 


\section{MATERIALS AND METHODS}

\section{Plant Growth and AM Inoculation}

Solanum lycopersicum L. (Mill.) cv. Moneymaker (accession LA0575), the ABA-deficient mutant sitiens (Taylor et al., 1988; accession LA3283) and its wild-type background cv. Rheinlands Ruhm (Accession LA0535), the GA-constitutive response mutant procera (Bassel et al., 2008) and its isogenic wild-type Ailsa Craig were used. Seed were obtained from the Tomato Genetics Resource Centre (TGRC) at the University of California, Davis, CA, USA. Tomato seed sterilization, AM fungi inoculation and plant growth were carried out according to the techniques described by Herrera-Medina et al. (2007). Plant growth and treatments were carried out in a growth chamber $(16: 8 \mathrm{~h}$, $24: 19^{\circ} \mathrm{C}$, day:night cycle; relative humidity 50\%). Inoculation with Rhizophagus irregularis (DAOM 197198; Schüßler and Walker, 2010) was carried out in $200 \mathrm{~mL}$ pots. Each seedling was grown in a separate pot and inoculated with a piece of monoxenic culture in a Gel-Gro medium (ICN Biochemicals, Aurora, OH, USA) containing $50 \mathrm{R}$. irregularis spores and infected carrot roots. The monoxenic culture ( $R$. irregularis and carrot roots) was produced according to the method described by Chabot et al. (1992). In the non-inoculated treatment, a piece of Gel-Gro medium containing only uninfected carrot roots was applied to the plants.

One week after planting in pots and weekly thereafter, $20 \mathrm{~mL}$ of a modified Long Ashton nutrient solution containing $0.325 \mathrm{mM} \mathrm{Pi}$ was added to prevent mycorrhizal inhibition by excess phosphorous (Hewitt, 1966). Non-mycorrhizal control plants received complete Long Ashton nutrient solution $(1.3 \mathrm{mM}$ $\mathrm{Pi}$ ). Plants were harvested at 50 days after inoculation, and the root system was washed, rinsed several times with sterilized distilled water, weighed and cut into pieces of about $1 \mathrm{~cm}$ pieces from each root system were mixed to obtain a homogenate mixture of the whole root system. Representative portions of this mixture were handled and used for different measurements according to the nature of the experiment. Root pieces for tripan blue staining were directly processed. Roots for RNA extractions were stored at $-80^{\circ} \mathrm{C}$ until use, and root pieces for hormone quantification were frozen and lyophilised. In each experiment, five independent plants were analyzed per treatment. Each plant was considered as a biological replicate. Sitiens plants were sprayed daily with water to prevent wilting.

\section{Estimation of Root Colonization}

The non-vital trypan blue histochemical staining procedure was used according to the Phillips and Hayman (1970) method. Stained roots were observed under a light microscope, and the intensity of root cortex colonization by the AM fungus was determined according to the procedure described by Trouvelot et al. (1986) using MYCOCALC software ${ }^{1}$. The parameters measured were frequency of colonization $(\% \mathrm{~F})$, intensity of colonization (\%M) and arbuscule abundance in the whole root $(\% \mathrm{~A})$ as well as arbuscule abundance in mycorrhizal root

\footnotetext{
${ }^{1}$ http://www.dijon.inra.fr/mychintec/Mycocalc-prg/download.html
}

fragments (\%a). At least three microscope slides were analyzed per root system, with each slide containing $301 \mathrm{~cm}$ root pieces.

The percentage of arbuscules at three distinct morphological stages of arbuscule formation was calculated according previous studies (Herrera-Medina et al., 2007). Class A are arbuscules in formation (or degradation) with no fine branches partially occupying the plant cell; class $\mathrm{B}$, arbuscules with at least some fine branches occupying almost all of the plant cell; class C, arbuscules with many branches occupying the whole plant cell. A brief description of the evaluation of arbuscule morphology was shown in Supplementary Figure S1.

\section{RNA Extractions and Gene Expression}

For the RT-PCR experiments, total RNA was isolated from $0.5 \mathrm{~g}$ sample taken from the root of each plant. Total RNA was isolated from the roots stored at $-80^{\circ} \mathrm{C}$ using the RNeasy Plant Mini Kit (Qiagen, Valencia, CA, USA) following the manufacturer's instructions.

cDNAs were obtained from $1 \mu \mathrm{g}$ of total DNAse-treated RNA in a $20 \mu \mathrm{L}$ reaction volume using the iScriptTM cDNA synthesis kit following the supplier's protocol (Bio-Rad, Hercules, CA, USA). qRT-PCR was carried out to measure the transcript abundance of the elongation factor $1 \alpha$ (GinEF) gene of $R$. irregularis, as well as SlPt4 and GA- and ABApathway related tomato genes. Primer names and corresponding sequences (Supplementary Table S1) were previously published. qRT-PCR was carried out using an iCycler apparatus (Bio-Rad, Hercules, CA, USA). Each $20 \mu \mathrm{L}$ PCR reaction contained $1 \mu \mathrm{L}$ of diluted cDNA (1:10), $10 \mu \mathrm{L} 2 \mathrm{x}$ SYBR Green Supermix (BioRad, Hercules, CA, USA) and $200 \mathrm{nM}$ of each primer using a 96-well plate. The PCR program consisted of a 3 min incubation at $95^{\circ} \mathrm{C}$, followed by 35 cycles of $30 \mathrm{~s}$ at $95^{\circ} \mathrm{C}, 30 \mathrm{~s}$ at $58-63^{\circ} \mathrm{C}$, and $30 \mathrm{~s}$ at $72^{\circ} \mathrm{C}$. The specificity of the PCR amplification procedure was checked using a melting curve after the final PCR cycle (70 steps of $30 \mathrm{~s}$ from 60 to $95^{\circ} \mathrm{C}$ at a heating rate of $0.5^{\circ} \mathrm{C}$ ). Experiments were carried out on three biological replicates, and the threshold cycle $(\mathrm{Ct})$ was determined in triplicate. The relative transcription levels were calculated by using the $2^{-\Delta \Delta C t}$ method (Livak and Schmittgen, 2001). The Ct values of all genes were normalized to the $\mathrm{Ct}$ value of the LeEF-1 (accession number X14449) housekeeping gene.

The qPCR data for each gene were shown as relative expression with respect to the control treatment ("reference treatment") to which it was assigned an expression value of 1 . The reference treatment generally corresponded to the non-AM inoculated treatment. When comparing different genes in a single experiment, qPCR data were showed as $M$-value (the $M$-value refers to $\log 2$ of the relative expression level).

\section{Chemical Treatments}

The tomato plants were treated in soil with ABA (Sigma), gibberellic acid $\left(\mathrm{GA}_{3}\right.$; Panreac, Barcelona, Spain), and prohexadione-calcium ( $\mathrm{PrCa} ; \mathrm{BASF}$ ). The $\mathrm{PrCa}$ is a late stage GA biosynthetic inhibitor that blocks $3 \beta$-hydroxylation and also prevents catabolism of $\mathrm{GA}_{1}$ to inactive $\mathrm{GA}_{8}$ by blocking $2 \beta$-hydroxylation (Brown et al., 1997). The solutions were prepared by dilution from a stock. Stock solutions contained 
$1 \mathrm{mM} \mathrm{ABA}, 100 \mu \mathrm{M} \mathrm{GA} 3$ and $1 \mathrm{mM} \mathrm{PrCa}$ in $1 \%$ ethanol. A $0.1 \%$ ethanol solution was used for the control treatments to compensate the ethanol content present in the hormonal solutions applied. The final $\mathrm{ABA}, \mathrm{GA}_{3}$, and $\mathrm{PrCa}$ concentrations were in the range of concentrations used in previous studies in which its effect on AM formation were determined (MartínRodríguez et al., 2010; Martín-Rodríguez et al., 2015). Twenty $\mathrm{ml}$ of the corresponding diluted solution were applied twice a week to each $200 \mathrm{~mL}$ pot containing one tomato plant. The first application was carried out 1 week after AM fungal inoculation.

\section{Hormone Quantification}

Abscisic acid quantification was repeated three times with each biological replicates. Freeze-dried roots (equivalent to a minimum of $100 \mathrm{mg}$ fresh weight of root material) were homogenized and extracted for $1 \mathrm{~h}$ in $1 \mathrm{~mL}$ cold methanol/water/acetic acid (80/19/1, v/v). Internal standard mixtures, containing 20 pmoL of each of $(-)-7^{\prime}, 7^{\prime}, 7^{\prime}-2 \mathrm{H}_{3}$-phaseic acid; (-)- $7^{\prime}, 7^{\prime}, 7^{\prime}-2 \mathrm{H}_{3}$-dihydrophaseic acid; (-)- $-8^{\prime}, 8^{\prime}, 8^{\prime}-2 \mathrm{H}_{3}$ neophaseic acid; (+)-4,5, $8^{\prime}, 8^{\prime}, 8^{\prime}-2 \mathrm{H}_{5}$-ABA-GE; (-) $-5,8^{\prime}, 8^{\prime}, 8^{\prime}$ $2 \mathrm{H}_{4}-7^{\prime}-\mathrm{OH}-\mathrm{ABA}$ and $(+)-3^{\prime}, 5^{\prime}, 5^{\prime}, 7^{\prime}, 7^{\prime}, 7^{\prime}-2 \mathrm{H}_{6}-\mathrm{ABA}$ were added to the samples. The homogenates were centrifuged $(21000 \times g$, $10 \mathrm{~min}, 4^{\circ} \mathrm{C}$ ) and the pellets were then re-extracted in $0.5 \mathrm{~mL}$ extraction solvent for $30 \mathrm{~min}$. The supernatants were dried under vacuum. Extracts were dissolved in $100 \mu \mathrm{L} 99 \%$ methanol:1\% acetic acid (v/v) topped up to $1 \mathrm{~mL}$ with $99 \%$ water: $1 \%$ acetic acid (v/v), purified by solid-phase extraction on an Oasis ${ }^{\circledR}$ HLB cartridges (60 mg, $3 \mathrm{~mL}$, Waters, Milford, MA, USA) and evaporated to dryness in a Speed-Vac (UniEquip). Subsequently the evaporated samples were methylated, purified by ABAspecific immunoaffinity extraction (Hradecká et al., 2007), and analyzed by UPLC-ESI(+)-MS/MS (Turečková et al., 2009).

Samples were analyzed for GA content according to Urbanová et al. (2013) with modifications (Martín-Rodríguez et al., 2015). Tomato root samples (10 mg freeze-dried dry weight) were homogenized using a MM 301 vibration mill (Retsch $\mathrm{GmbH}$ and Co. KG, Haan, Germany) in $2 \mathrm{~mL}$-Eppendorf tubes with $1 \mathrm{~mL} 80 \%$ acetonitrile containing 5\% formic acid after adding internal standard mixture containing 50 pmol each of ${ }^{2} \mathrm{H}_{2}$ labeled GAs $\left(\left[{ }^{2} \mathrm{H}_{2}\right] \mathrm{GA}_{1},\left[{ }^{2} \mathrm{H}_{2}\right] \mathrm{GA}_{3},\left[{ }^{2} \mathrm{H}_{2}\right] \mathrm{GA}_{4},\left[{ }^{2} \mathrm{H}_{2}\right] \mathrm{GA}_{5}\right.$, $\left[{ }^{2} \mathrm{H}_{2}\right] \mathrm{GA}_{6}, \quad\left[{ }^{2} \mathrm{H}_{2}\right] \mathrm{GA}_{7}, \quad\left[{ }^{2} \mathrm{H}_{2}\right] \mathrm{GA}_{8}, \quad\left[{ }^{2} \mathrm{H}_{2}\right] \mathrm{GA}, \quad\left[{ }^{2} \mathrm{H}_{2}\right] \mathrm{GA}_{12}$, $\left[{ }^{2} \mathrm{H}_{2}\right] \mathrm{GA}_{12 \mathrm{ald}},\left[{ }^{2} \mathrm{H}_{2}\right] \mathrm{GA}_{15},\left[{ }^{2} \mathrm{H}_{2}\right] \mathrm{GA}_{19},\left[{ }^{2} \mathrm{H}_{2}\right] \mathrm{GA}_{20},\left[{ }^{2} \mathrm{H}_{2}\right] \mathrm{GA}_{24}$, $\left[{ }^{2} \mathrm{H}_{2}\right] \mathrm{GA}_{29},\left[{ }^{2} \mathrm{H}_{2}\right] \mathrm{GA}_{34},\left[{ }^{2} \mathrm{H}_{2}\right] \mathrm{GA}_{44},\left[{ }^{2} \mathrm{H}_{2}\right] \mathrm{GA}_{51}$, and $\left[{ }^{2} \mathrm{H}_{2}\right] \mathrm{GA}_{53}$; OlChemIm, Olomouc, Czech Republic). The tubes were then placed in a fridge $\left(4^{\circ} \mathrm{C}\right)$ and extracted overnight by stirring at $15 \mathrm{rpm}$ using a bench top laboratory rotator Stuart SB $3^{2}$. The homogenates were centrifuged at $19000 \mathrm{rpm}$ for $10 \mathrm{~min}$ at $4^{\circ} \mathrm{C}$ using a Beckman Avanti ${ }^{\mathrm{TM}} 30$ centrifuge ${ }^{3}$. Supernatants were further purified using mixed mode anion exchange cartridges ${ }^{4}$ and analyzed by ultra-high performance chromatography (Acquity UPLC ${ }^{\mathrm{TM}}$ System; Waters) coupled to a triple-stage quadrupole mass spectrometer (Xevo ${ }^{\circledR}$ TQ MS, Waters MS Technologies, Manchester, UK) equipped with an electrospray

\footnotetext{
${ }^{2}$ http://www.bibby-scientific.com

${ }^{3}$ http://www.beckmancoulter.com

${ }^{4}$ http://www.waters.com
}

(ESI) interface. Gibberellins were detected in multiple-reaction monitoring (MRM) mode based on the transition of the precursor ion $[\mathrm{M}-\mathrm{H}]$ - to the appropriate product ion. Data were obtained and processed by Masslynx 4.1 software (Waters) and GA levels were calculated using the standard isotope-dilution method (Rittenberg and Foster, 1940).

\section{Statistical Analysis}

Data were analyzed by general linear model analysis of variance (ANOVA), with subsequent comparison between means using Duncan's multiple range test $(P=0.05)$. Correlation and regression analysis was done using Microsoft Excel 2010 software.

\section{RESULTS AND DISCUSSION}

Plant hormones mostly work in combination, with hormonal balance being critical for short- and long-term responses. In several plant species has now been established that ABA plays a largely positive role in AM, while GAs acting through DELLAs have a negative role. Most evidence derives from pharmacological or genetic approaches through the analysis of plants with altered hormone biosynthesis or signaling (Pozo et al., 2015). In this study, we attempt to demonstrate that the role played by ABA in AM formation could, at least in part, be attributable to antagonistic interactions with GAs and to explore the possible ways in which ABA and GAs interact to control AM.

\section{Metabolism and Distribution of ABA in Arbuscular Mycorrhizal Tomato Roots}

Our results show that differences in ABA metabolism between control and mycorrhizal roots exist (Table 1). In tomato roots, the main ABA metabolism pathway appears to go through $8^{\prime}$ - hydroxylation (resulting in PA which is further reduced to DPA) and conjugation (resulting in ABA-GE). Secondary catabolism pathways like $7^{\prime}$ - and $9^{\prime}$-hydroxylation (resulting in $7^{\prime}-\mathrm{OH} \mathrm{ABA}$ and neoPA) are also present. Mycorrhizal roots showed a slight increase in free ABA and possess smaller amounts of ABA catabolites and much less ABA-GE than that in nonmycorrhizal roots (Table 1 ). The presence of ABA catabolites suggests that bioactive ABA was previously biosynthesized in the

\begin{tabular}{lccc}
\multicolumn{4}{l}{ TABLE 1 | Abscisic acid metabolites content $(\mathbf{n g} / \mathbf{g}$ DW) in tomato roots. } \\
\hline & Control (C) & Mycorrhizal (M) & Ratio $\mathbf{~ M / C ~}$ \\
\hline Free ABA & $99 \pm 2.8^{\mathrm{a}}$ & $137 \pm 19.2^{\mathrm{b}}$ & 1.38 \\
ABA-GE & $1598 \pm 284.7^{\mathrm{a}}$ & $311 \pm 27.7^{\mathrm{b}}$ & 0.19 \\
DPA & $276 \pm 41^{\mathrm{a}}$ & $228 \pm 80^{\mathrm{a}}$ & 0.82 \\
PA & $59 \pm 2.13^{\mathrm{a}}$ & $9 \pm 0.3^{\mathrm{b}}$ & 0.15 \\
$7^{\prime} \mathrm{OH}-\mathrm{ABA}$ & $\mathrm{ND}$ & $8 \pm 3.3^{\mathrm{a}}$ & $\geq 8$ \\
neo-PA & $13 \pm 3.1^{\mathrm{a}}$ & $5 \pm 0.9^{\mathrm{b}}$ & 0.38
\end{tabular}

Levels of ABA, ABA-GE, DPA, PA, $7^{\prime} \mathrm{OH}-\mathrm{ABA}$ and neo-PA were measured by UPLC-ESI(+)-MS/MS from roots of non-mycorrhizal (control) and mycorrhizal plants 50 days after inoculation with Rhizophagus irregularis. Values correspond to mean $\pm S E(n=5)$. For each compound values with same letters do not significantly differ $(P=0.05)$ according to Duncan's multiple range test. 
tissue and then rapidly metabolized. A comparative analysis of ABA metabolite distribution in non-inoculated and inoculated plant roots it shown in Supplementary Figure S2. Significantly, ABA-GE metabolite constitutes $80 \%$ of total ABA in control roots, and only $43 \%$ in colonized roots, while free $\mathrm{ABA}$ accounts $20 \%$ of total ABA in mycorrhizal roots and only $7 \%$ in the controls.

The concentration of ABA is regulated by catabolism as well as synthesis. ABA hydroxylation is catalyzed by cytochrome $\mathrm{P} 450$ mono-oxygenases (CYP707A) and, in tomato, we identified five cytochrome $\mathrm{P} 450$ proteins that contain the highly conserved cysteine residue (within the PFGNGTHSCPG motif), which is the putative heme-iron ligand, common to all P450s and essential for catalytic activity (Kushiro et al., 2004), and putatively encode ABA hydroxylases (Supplementary Table S1). Additionally, we detected two tomato NCED that catalyze the major ratelimiting step and point of regulation in ABA biosynthesis (Supplementary Table S1). Real-time PCR analysis revealed differences in gene expression between control and inoculated tomato roots. SINCED1 and SINCED2 are equally expressed in mycorrhizal and non-mycorrhizal roots, although SINCED1 was expressed approximately 30 times more than SINCED2 (Figure 1). Gene expression data in combination with the results of ABA measurements suggest that some alterations in $\mathrm{ABA}$ catabolites could be due to differential regulation of ABAhydroxylation related genes. Thus, four genes encoding putative ABA hydroxylases are responsive to colonization, two of which (SlCYP707A1 and SlCYP707A3-like) are up-regulated and two

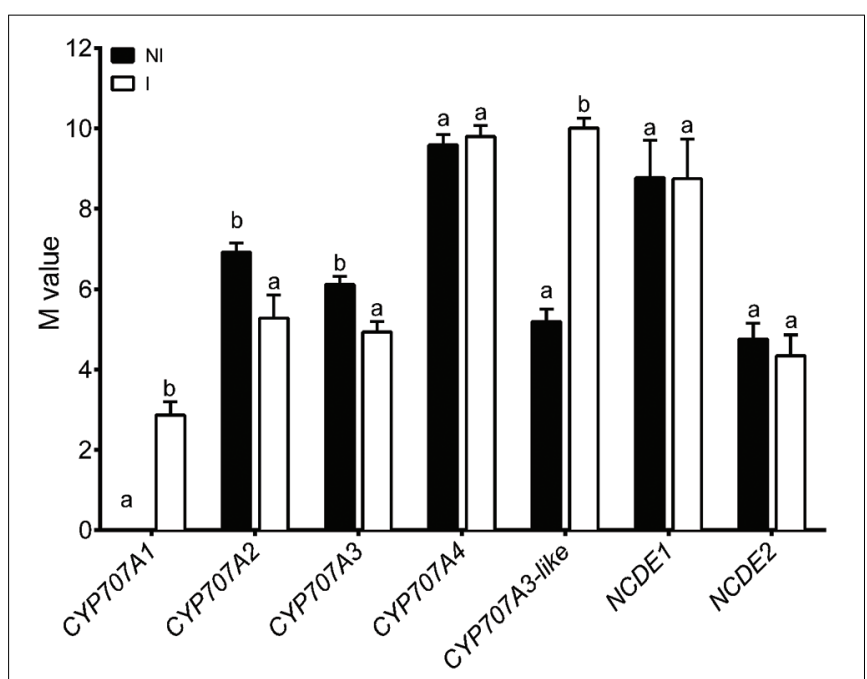

FIGURE 1 | Abscisic acid metabolism-related gene expression in roots of Moneymaker tomato plants non-colonized (NI) or colonized with $\boldsymbol{R}$. irregularis (I). Gene expression was measured by qPCR 50 days after inoculation. qPCR data represent the expression of target genes as $M$-value with respect the expression of CYP707A1 in non-colonized plants (the biological replicate with lower expression) in which the expression was designated to be $M=0$ and all other samples were expressed relative to it. Values correspond to mean $\pm \mathrm{SE}(n=3)$. For each gene, bars with same letters are not significantly different $(P=0.05)$ according to Duncan's multiple range test.
(SlCYP707A2 and SlCYP707A3) repressed in mycorrhizal roots (Figure 1). These data are fully in line with these provided by of Fiorilli et al. (2009), who suggest that active synthesis and catabolism of ABA occur in mycorrhizal roots and provide evidence of the presence of a CYP707A gene that is specifically expressed in arbuscule-containing cells. All the data related to the study of ABA during AM formation support the hypothesis that a balance between the biosynthesis and catabolism of ABA is crucial for the differentiation of arbuscules in tomato (HerreraMedina et al., 2007; Fiorilli et al., 2009; García-Garrido et al., 2010; this study).

A role for ABA in the mechanisms by which AM symbiosis influences water stress has recently been suggested (LudwigMüller, 2010; Ruiz-Lozano et al., 2016). Recent results showed a steady increase in ABA content in tomato roots from nonAM plants as a consequence of water stress, reaching the maximum ABA levels under severe stress. A similar trend as for non-AM plants was observed for AM plants, even though mycorrhizal tomato plants showed a significant lower level of ABA in roots compared to non-AM plants (Chitarra et al., 2016; Ruiz-Lozano et al., 2016). In plants, two pathways promote free ABA accumulation: NCED-mediated de novo synthesis and betaglucosidase-mediated hydroxylation (Lee et al., 2006). It was demonstrated that $\beta$-glucosidases from Arabidopsis can catalyze the release of ABA-GE into free ABA for involvement in stomatal movement, early seed germination, and abiotic stress (Lee et al., 2006). This release of ABA from ABA-GE pools is an important mechanism for regulating ABA levels. Therefore, it is conceivable that the differences in the accumulation of free ABA under water stress between non-mycorrhizal and mycorrhizal tomato plants (Chitarra et al., 2016; Ruiz-Lozano et al., 2016) could be a consequence of the lower ABA-GE content in mycorrhizal plants, as it has been demonstrated here.

\section{GA Metabolism in Low ABA Mutant}

As previously shown (Martín-Rodríguez et al., 2015), GA metabolism from the 13-hydroxylation pathway sharply increased in tomato mycorrhizal roots. To test if ABA interferes with the GA metabolism upon mycorrhization, we analyzed the differences in GA concentration and GA-related gene expression between wild-type mycorrhizal plants and ABA-deficient mutant plants which have shown mycorrhizal impairment (Herrera-Medina et al., 2007).

Arbuscular mycorrhiza functionality was quantified as SIPT4 gene expression as SIPT4 encodes an AM-specific phosphate transporter protein whose transcript levels are a measure of arbuscule functionality (Balestrini et al., 2007). Fungal colonization significantly increased SIPT4 gene expression in wild-type plants, while only a slight increase in transcript accumulation was detected in mycorrhizal sitiens plants (Figure 2). These data reflect the impairment of ABA-deficient plants in terms of establishing functional mycorrhization.

The expression pattern of GA biosynthesis-related genes coding for CPS, GA 20-oxidase 1 (GA20ox1) and GA 3-oxidase 1 (GA3ox1) was analyzed. For all three genes, expression levels were higher in the roots of wild-type mycorrhizal plants than in wild-type non-mycorrhizal plants. Gene expression levels in 

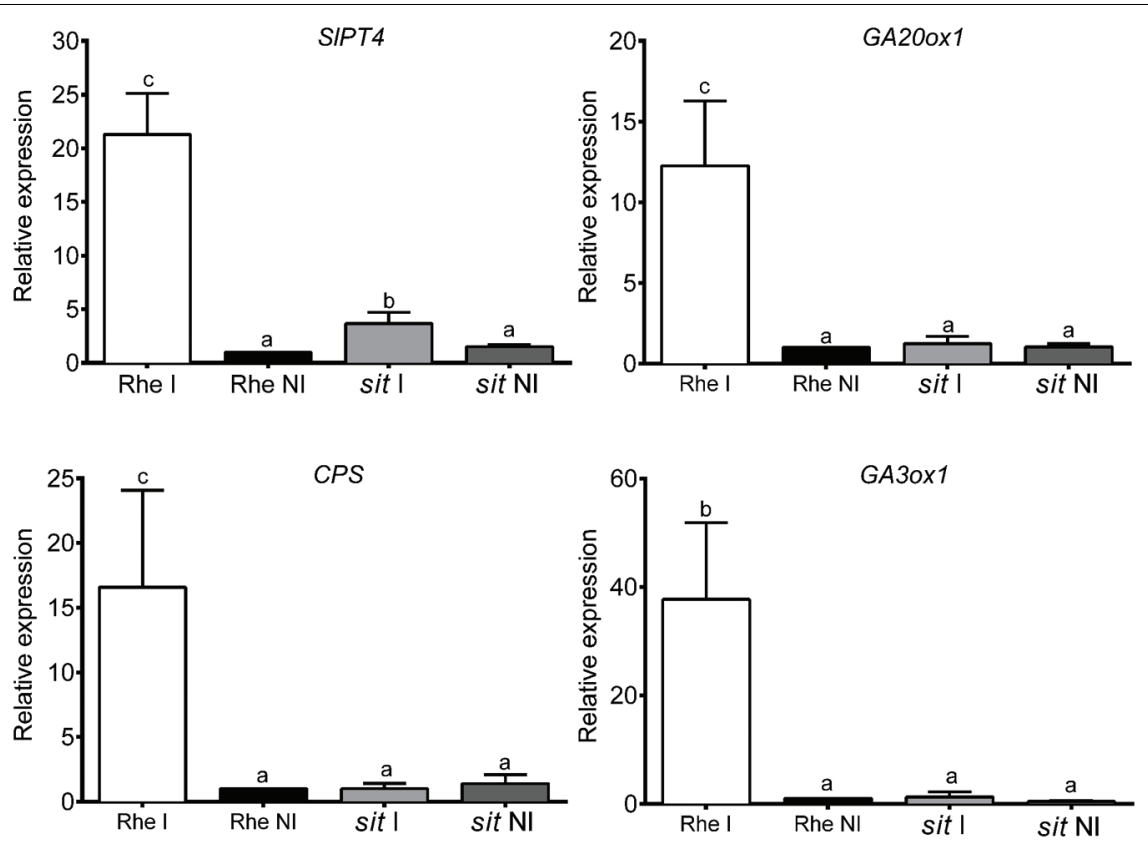

FIGURE 2 | SIPT4 and GA metabolism-related gene expression in roots of Rheinland Ruhm (Rhe) and sitiens (sit) tomato plants non-colonized (NI) and colonized (I) with $\boldsymbol{R}$. irregularis. After 1 week of transplanting, plants were inoculated with $R$. irregularis and gene expression was measured by qPCR 50 days after inoculation. QPCR data represent the relative expression of target genes in plants with respect to expression in Rheinland Ruhm non-colonized plants in which expression was designated as 1. Values correspond to mean $\pm \mathrm{SE}(n=3)$. For each gene, bars with same letters are not significantly different $(P=0.05)$ according to Duncan's multiple range test.

the roots of both mycorrhizal and non-mycorrhizal sitiens plants were similar to those found in wild-type non-mycorrhizal plants (Figure 2).

Concentrations of several endogenous GAs were measured in the roots of wild-type and sitiens plants relative to their mycorrhization capacity (Supplementary Figure S3). Colonization of wild-type tomatoes caused an increase in active $\mathrm{GA}_{1}$ and $\mathrm{GA}_{3}$ compounds, derived from the 13-hydroxylation pathway, relative to those in the non-mycorrhizal controls, while a decrease in the $\mathrm{GA}_{5}$, a precursor of $\mathrm{GA}_{3}$, was observed (Supplementary Figure S3). In the case of sitiens plants, no major changes were observed in GA content associated with either, ABA deficiency or mycorrhization. Only $\mathrm{GA}_{19}$ content increased following colonization, while non-mycorrhizal and mycorrhizal sitiens plants showed similar $\mathrm{GA}_{44}$ and $\mathrm{GA}_{5}$ levels than wild-type mycorrhizal plants (Supplementary Figure S3).

In conclusion, the increases of GAs were either absent or less pronounced in the impaired mycorrhizal ABA-deficient sitiens mutant than in wild-type plants, with only a slight increase in the expression of GA catabolism and GA responsive genes being associated with ABA-deficiency. These results suggest that a functional and well-established colonization is necessary for the expression of GA-related genes in mycorrhizal roots. They also clearly show that the increase in GA levels in mycorrhizal roots is a consequence of a symbiosis-induced mechanism that requires well-established colonization and functional arbuscules which in turn is dependent on a functional ABA pathway (Herrera-Medina et al., 2007; Martín-Rodríguez et al., 2011).

\section{ABA Influences GAs and then Influence AM Formation}

A set of experiments were carried out in order to establish a link between $\mathrm{ABA} / \mathrm{GA}$ imbalance and regulation of $\mathrm{AM}$ formation. Firstly, arbuscule abundance (\%a) in mycorrhizal root fragments was determined in Ailsa Craig wild-type and procera (a GAconstitutive response tomato mutant) plants treated with $\mathrm{ABA}$ (Figure 3A). Non-treated procera plants showed lower arbuscule abundance levels in roots than wild-type plants. However, ABA treatment rescued the \%a values for procera roots, bringing them into the same range as those recorded for wild-type plant roots. ABA treatment did not increase \%a in wild-type plants (Figure 3A).

Secondly, arbuscule abundance (\%a) in the mycorrhizal root fragments of wild-type plants treated with $A B A, G A_{3}$, and $A B A+G_{3}$ was determined (Figure 3B). Although, $G_{3}$ treatment negatively affected \%a in wild-type mycorrhizal tomato roots, this parameter was shown to be partially rescued when $\mathrm{ABA}$ was combined with the application of $\mathrm{GA}_{3}$, reaching $75 \%$ as compared to the value observed for non-treated plants (Figure 3B). Fungal colonization was also quantified as SlPT4 gene expression. As with \%a, $\mathrm{GA}_{3}$ treatment decreased SlPT4 gene expression in mycorrhizal roots, while $\mathrm{ABA}$ rescued the negative impact of GA when both compounds were applied together (Figure 3C).

The negative effect on arbuscule abundance due to the applications of $\mathrm{GA}_{3}$ to wild-type plants, and the depletion of arbuscules in procera mutant plants carrying a mutation in 


\section{A}

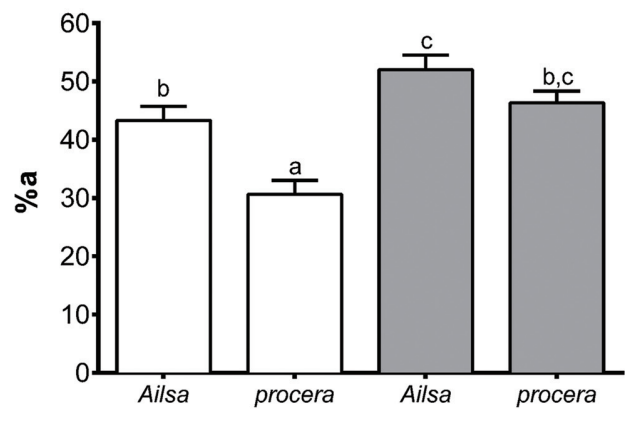

B

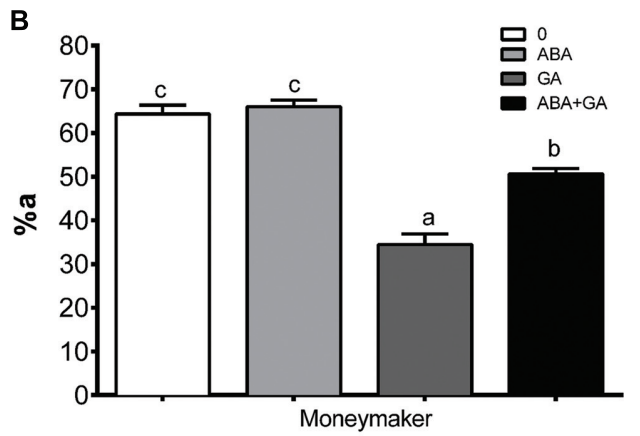

C

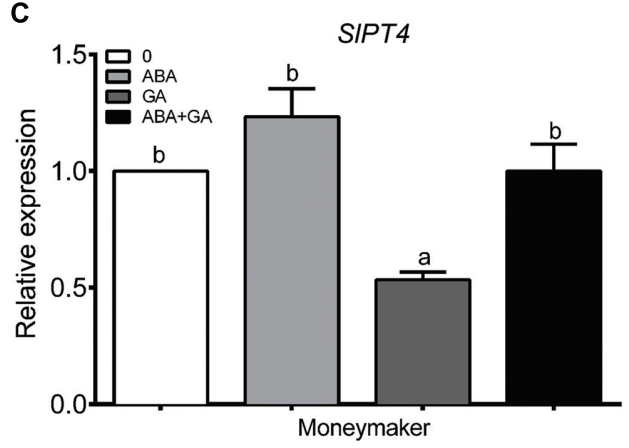

FIGURE 3 | Arbuscular abundance in mycorrhizal roots of non-treated Ailsa Craig and procera plants $(A)$ and arbuscular abundance $(B)$ and SIPT4 gene expression (C) in Moneymaker tomato plants after ABA and GA applications. After 1 week of transplanting and inoculation with

R. irregularis, plants were treated with $\mathrm{ABA}(75 \mu \mathrm{M})$ and $\mathrm{GA} 3(5 \mu \mathrm{M})$. Solutions were applied to soil twice per week and mycorrhization was measured

50 days after inoculation. Arbuscular abundance (a\%) in mycorrhizal zones of the root was determined using MYCOCALC software. GPCR data represent the expression of SIPT4 gene in treated plants with respect to expression in non-treated plants in which expression was designated as 1. Values correspond to mean \pm SE $(n=3)$. Bars with same letters do not significantly differ $(P=0.05)$ according to Duncan's multiple range test.

the gene encoding SIDELLA, a repressor in the GA-signaling pathway (Bassel et al., 2008), were both partly offset by the application of $\mathrm{ABA}$. The fact that $\mathrm{ABA}$ can rescue arbuscules in procera mutant plants lacking a functional DELLA protein means that the effect of ABA applications should not be attributed to DELLA stabilization which is the main target of ABA/GA interaction and suggests that $\mathrm{ABA}$ may act downstream and independently of GA signaling. Nonetheless, procera is a leaky mutant, the constitutive GA response conferred by the pro mutation is not saturated (Van Tuinen et al., 1999), and these mutant plants are responsive to $\mathrm{GA}_{3}$. Thus, $\mathrm{ABA}$ could also act upstream of GA signaling modulating GA levels. In this respect, it has been established that the stabilization of DELLAs by ABA treatments in Arabidopsis plants is achieved by reducing GA accumulation (Zentella et al., 2007).

Gene transcripts accumulation as well as the metabolites concentration related to GA and ABA metabolism were measured in $\mathrm{ABA}, \mathrm{GA} 3$, and $\mathrm{ABA}+\mathrm{GA} 3$ treated plants. The expression patterns of GA biosynthesis-related genes (CPS, GA30x1, and GA20ox4) and GA catabolism genes (GA2ox3, GA2ox4, and GA20x5) were quantified using $\mathrm{qPCR}$ (Figures 4A,B). All genes, except GA2ox3, exhibited positive regulation under mycorrhizal conditions. The application of exogenous $\mathrm{ABA}$ or $\mathrm{GA}_{3}$ reduced gene expression of biosynthesis-related genes (Figure 4A) although ABA treatment did so to a lesser extent than $\mathrm{GA}_{3}$ treatment. Unlike GA biosynthesis-related genes, the GA catabolism genes analyzed showed a significant and similar positive response to $\mathrm{GA}_{3}$ and $\mathrm{ABA}$ treatments, increasing their expression relative to non-treated roots (Figure 4B). Accordingly, the application of exogenous ABA caused a decrease in bioactive $\mathrm{GA}_{1}$ (the bioactive $\mathrm{GA}$ activated during $\mathrm{AM}$ ) content in roots, while that of $\mathrm{GA}_{6}$ and $\mathrm{GA}_{7}$ catabolites increased (Figure 5). $\mathrm{GA}_{6}$ and $\mathrm{GA}_{7}$ are products of the catabolic action of GA2-/GA3-oxidases to $\mathrm{GA}_{5}$ and $\mathrm{GA}_{20}$ which are the precursors of $\mathrm{GA}_{1}$ and $\mathrm{GA}_{3}$, respectively. Interestingly, a feedback accumulation of $\mathrm{GA}_{1}$ and $\mathrm{GA}_{3}$ was observed following by exogenous $\mathrm{GA}_{3}$ application simultaneously with a negative effect on the level of their precursor, $\mathrm{GA}_{19}$. This impact was more pronounced in mycorrhizal roots than in non-mycorrhizal roots. This phenomenon is probably due to the inherent activation of the GA metabolism in mycorrhizal plants; remarkably, ABA applications interfere with this GA burst in mycorrhizal roots, implying that $\mathrm{ABA}$ is capable of regulating GA metabolism.

The application of $\mathrm{GA}_{3}$ promotes $\mathrm{GA}$ catabolism, measured as increases in $\mathrm{GA}_{8}, \mathrm{GA}_{6}$ and $\mathrm{GA}_{7}$ (more noticeable in mycorrhizal roots). Consistent with the increased GA-catabolic gene expression in roots treated with $\mathrm{ABA}$ (Figure 4B), the presence of exogenous $A B A$ caused a decrease in $\mathrm{GA}_{1}$ content while $\mathrm{GA}_{6}$ and $\mathrm{GA}_{7}$ catabolite content increased. The application of $\mathrm{ABA}$ in combination with $\mathrm{GA}_{3}$ interferes with the positive effect on $\mathrm{GA}_{1}$ and $\mathrm{GA}_{3}$ content caused by exogenous $\mathrm{GA}_{3}$ applications (Figure 5).

Altogether, the results show that $\mathrm{ABA}$ attenuated the expression of GA-biosynthetic genes and increased GA-catabolic gene expression in roots, two events which should lead to a reduction in bioactive GAs.

GA also regulated ABA metabolism in tomato roots. ABA$\mathrm{GE}$, free $\mathrm{ABA}$ and $\mathrm{ABA}$ catabolite levels were also determined in root samples (Figure 6). Exogenous applications of $A B A$ enhance endogenous free $\mathrm{ABA}$ content and activate its own catabolism. $\mathrm{GA}_{3}$ application partially blocks the accumulation of free $\mathrm{ABA}$ promoting ABA glycosylation. Further, DPA and ABA-GE, which are less abundant in mycorrhizal roots than in non-mycorrhizal roots, increased after $\mathrm{GA}_{3}$ applications suggesting that $\mathrm{GA}_{3}$ 


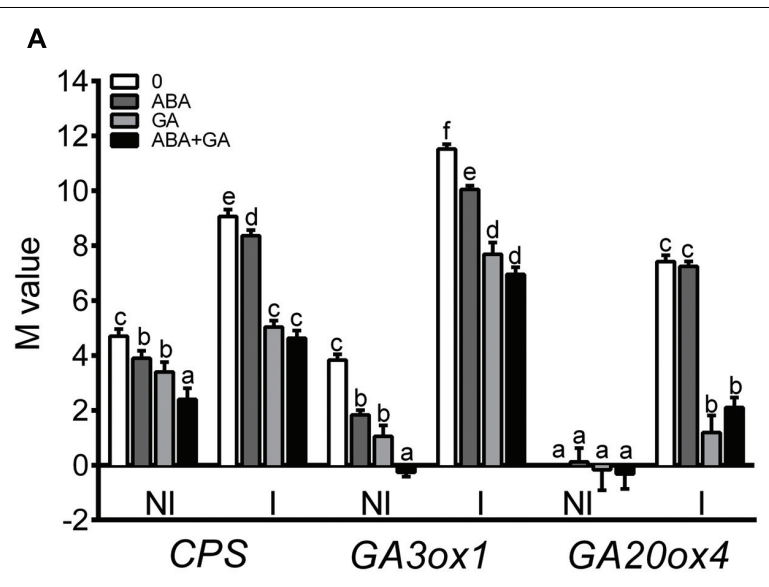

B

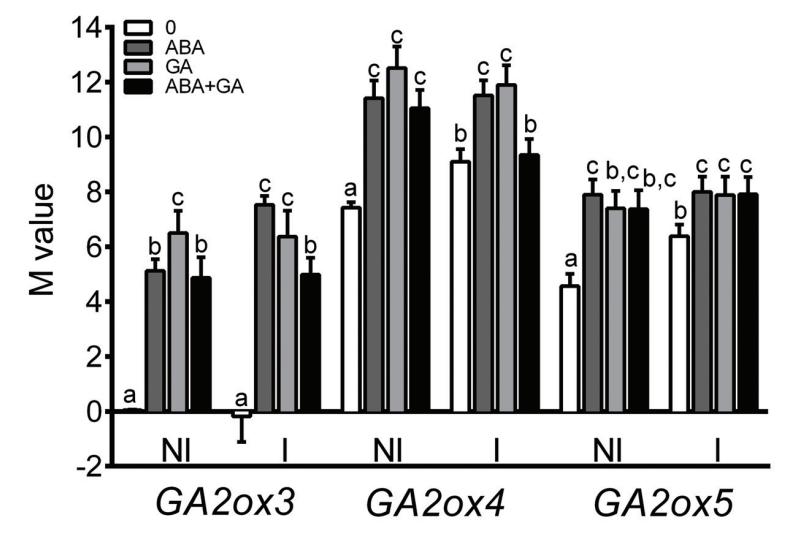

C

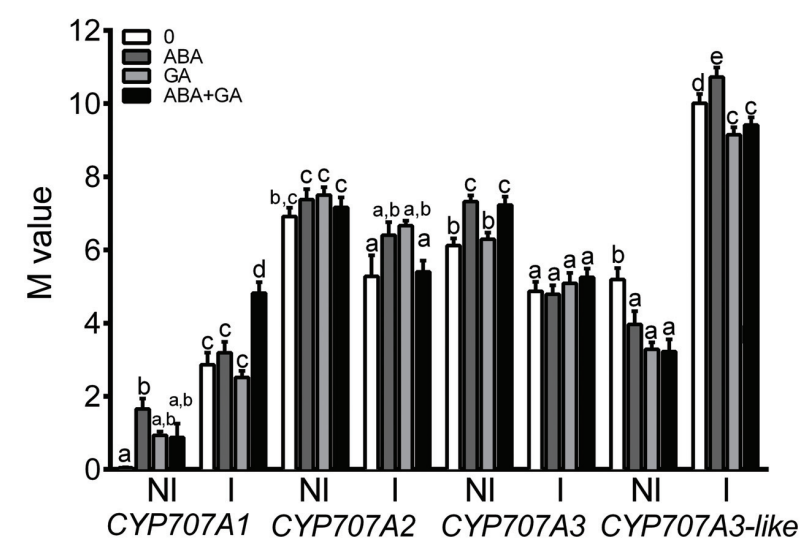

FIGURE 4 | Effect of $A B A$ and $\mathrm{GA}_{3}$ applications on GA biosynthesis (A) GA catabolism (B) and ABA catabolism-related (C) gene expression in roots of Moneymaker tomato plants non-colonized (NI) or colonized with $\boldsymbol{R}$. irregularis (I). After 1 week of transplanting and inoculation with R. irregularis, a set of tomato plants (control) were treated with $0.1 \%$ ethanol solution, and three sets of plants were treated with $A B A, G_{3}$ and $G_{3}+A B A$. GA3 $(5 \mu \mathrm{M})$ and ABA $(75 \mu \mathrm{M})$ solutions were applied to soil twice per week. Gene expression was measured by qPCR 50 days after inoculation. qPCR data represents expression as $M$-value in gene expression relative to the biological replicate with lower expression in which the expression was designated to be 0 and all other samples were expressed relative to it. Values correspond to mean $\pm \mathrm{SE}(n=3)$. For each gene, bars with same letters are not significantly different $(P=0.05)$ according to Duncan's multiple range test. enhanced the inactivation of $\mathrm{ABA}$ by $8^{\prime}$-hydroxylation in mycorrhizal roots. Meanwhile, the content of $7^{\prime}-\mathrm{OH}-\mathrm{ABA}$, which was activated after ABA treatment, was higher in mycorrhizal roots (Figure 6). These results as a whole suggest that GAs activate ABA catabolism and that mycorrhizal roots are more susceptible to this activation. This means that the GAs applied impact on the decrease in ABA content, a phenomenon that has previously been suggested in relation to lettuce seed germination through enhancement of ABA catabolism by gibberellins (Gonai et al., 2004).

Only small changes in gene expression related to $\mathrm{ABA}$ metabolism were observed following exogenous applications of the compounds (Figure 4C) and consequently, it is difficult to establish a correlation between the accumulation of catabolites and the expression of ABA metabolism-related genes. Thus, CYP707A1 gene expression was activated by $\mathrm{ABA}+\mathrm{GA}_{3}$ treatment mainly in mycorrhizal roots, whereas $A B A$ and $G_{3}$ applications upregulated CYP707A2 expression. CYP707A3 gene expression was increased in non-mycorrhizal roots after $A B A$ and $\mathrm{ABA}+\mathrm{GA}_{3}$ treatments, and CYP707A3-like expression seems to be downregulated by all treatments except in mycorrhizal roots treated with ABA (Figure 4C). NCED1 and NCDE2 gene expression were unaffected by chemical treatments (data not shown).

\section{ABA/GAs Imbalance in Sitiens: Inhibition of GA Biosynthesis has Similar Effect than ABA Application on Mycorrhizal Recovery in the Low ABA Mutant}

Arbuscular mycorrhizal development in sitiens plants is impaired due to ABA deficiency but is not directly associated with an increase in GA content (Supplementary Figure S3). Nevertheless this could be associated with greater responsiveness to GAs as a consequence of the $\mathrm{ABA} / \mathrm{GA}$ imbalance in sitiens roots. Thus, we determined whether the breakdown of this imbalance affects the GA hormone pathway in this mutant which is more responsive to ABA application. Previous studies have shown that the small percentage of arbuscules observed in mycorrhizal sitiens plants is mainly caused by the suppression of ABA biosynthesis in these mutants and that applications of $\mathrm{ABA}$ resulted in normal values for arbuscule abundance in mycorrhizal sitiens roots (HerreraMedina et al., 2007; Martín-Rodríguez et al., 2011).

We studied here the effects on mycorrhization and GA metabolism of sitiens plants treated with different combinations of $\mathrm{ABA}$ and $\mathrm{GA}_{3}$. While the application of $\mathrm{GA}_{3}$ reduced $\% \mathrm{~F}$ and had no impact on the other mycorrhization parameters, the application of exogenous ABA increased all the mycorrhization parameters for sitiens plants, particularly \%a and \%A (65 and $85 \%$, respectively; Figure 7A). The positive effect of ABA applications on $\% \mathrm{~F}, \% \mathrm{a}$, and $\% \mathrm{~A}$ was attenuated when $\mathrm{ABA}$ was applied together with $\mathrm{GA}_{3}$. Nevertheless, the positive effect of ABA increasing \%M occurred independently of the application of $\mathrm{GA}_{3}$ (Figure 7A). The high level of arbuscules in roots after ABA treatment probably triggers an increase in the colonization rate which also increases the intensity of colonization $(\% \mathrm{M})$. Contrary to what occurred with respect to arbuscule abundance, 


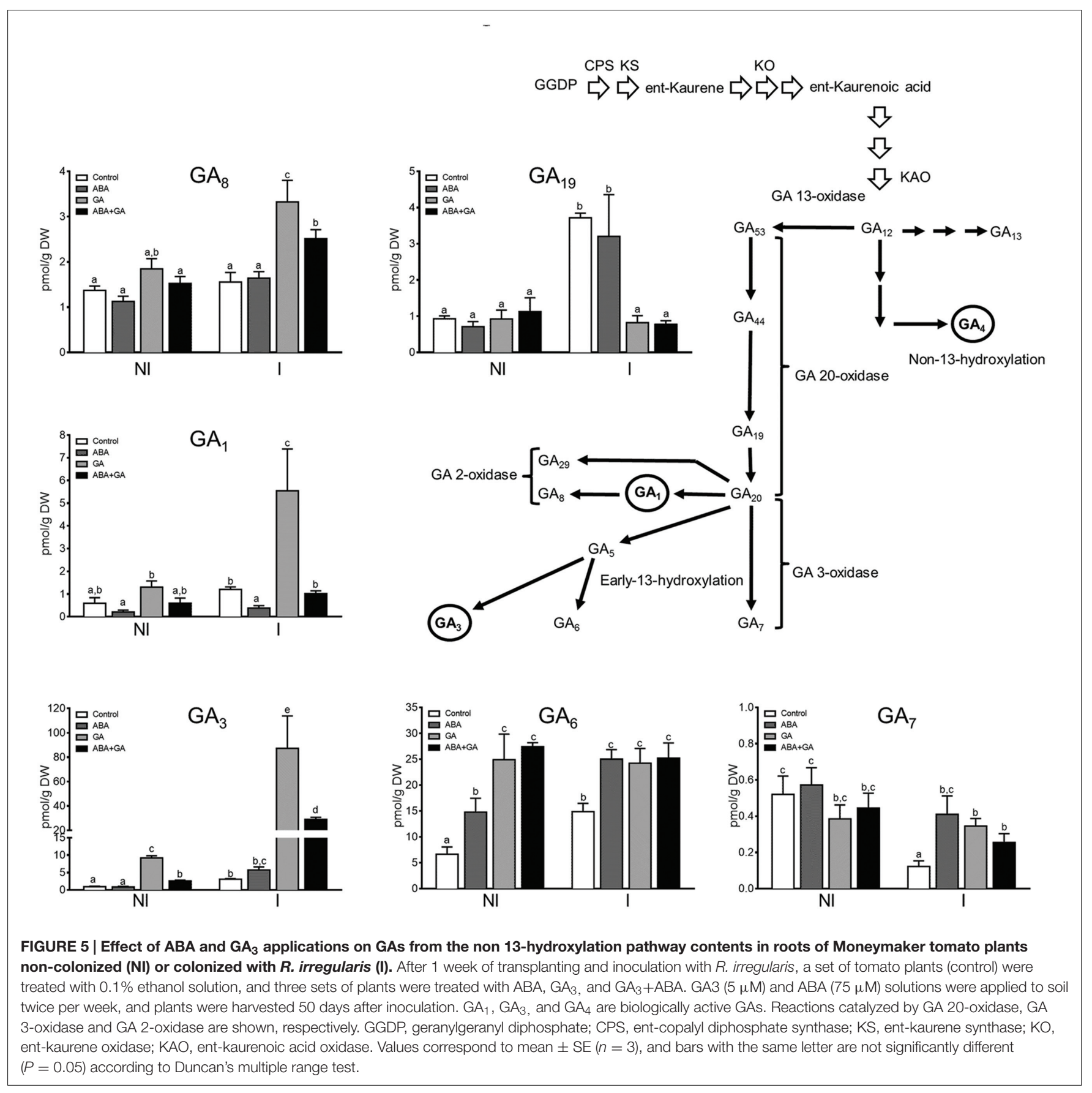

this positive effect was not eliminated when $\mathrm{GA}_{3}$ was applied in combination with ABA, suggesting that the positive effect of ABA on mycorrhizal intensity is independent of GAs.

The percentages of each arbuscule class (Supplementary Figure S1) for the different treatments differed greatly and confirmed the microscopic measurements of mycorrhization parameters. In sitiens plants, both untreated and treated with $\mathrm{GA}_{3}$, the majority of the arbuscules were in class A (less branched; 50 and $55 \%$, respectively), with only $20 \%$ in class B (intermediate branched; Figure 7B). Conversely, in plants treated with ABA, the majority of arbuscules were in class C (full branched; 50\%) with only $20 \%$ in class A (Figure 7B). However, with respect to plants treated with $\mathrm{ABA}$ in conjunction with $\mathrm{GA}_{3}$, the three classes of arbuscules were present in similar proportions (Figure 7B). Interestingly, a close linear and inverse correlation was observed between treatments in relation to the percentage of arbuscules in classes $\mathrm{A}$ and $\mathrm{C}\left(r^{2}=-0.95\right)$.

GinEF gene expression, which determines the rate of fungal colonization, increased threefold with $\mathrm{ABA}$ treatment and twofold in $\mathrm{ABA}+\mathrm{GA}_{3}$ treated plants (Figure 7C), while no significant change was observed with $\mathrm{GA}_{3}$ treatment. The expression of SIPT4, a plant gene marker for arbuscules 

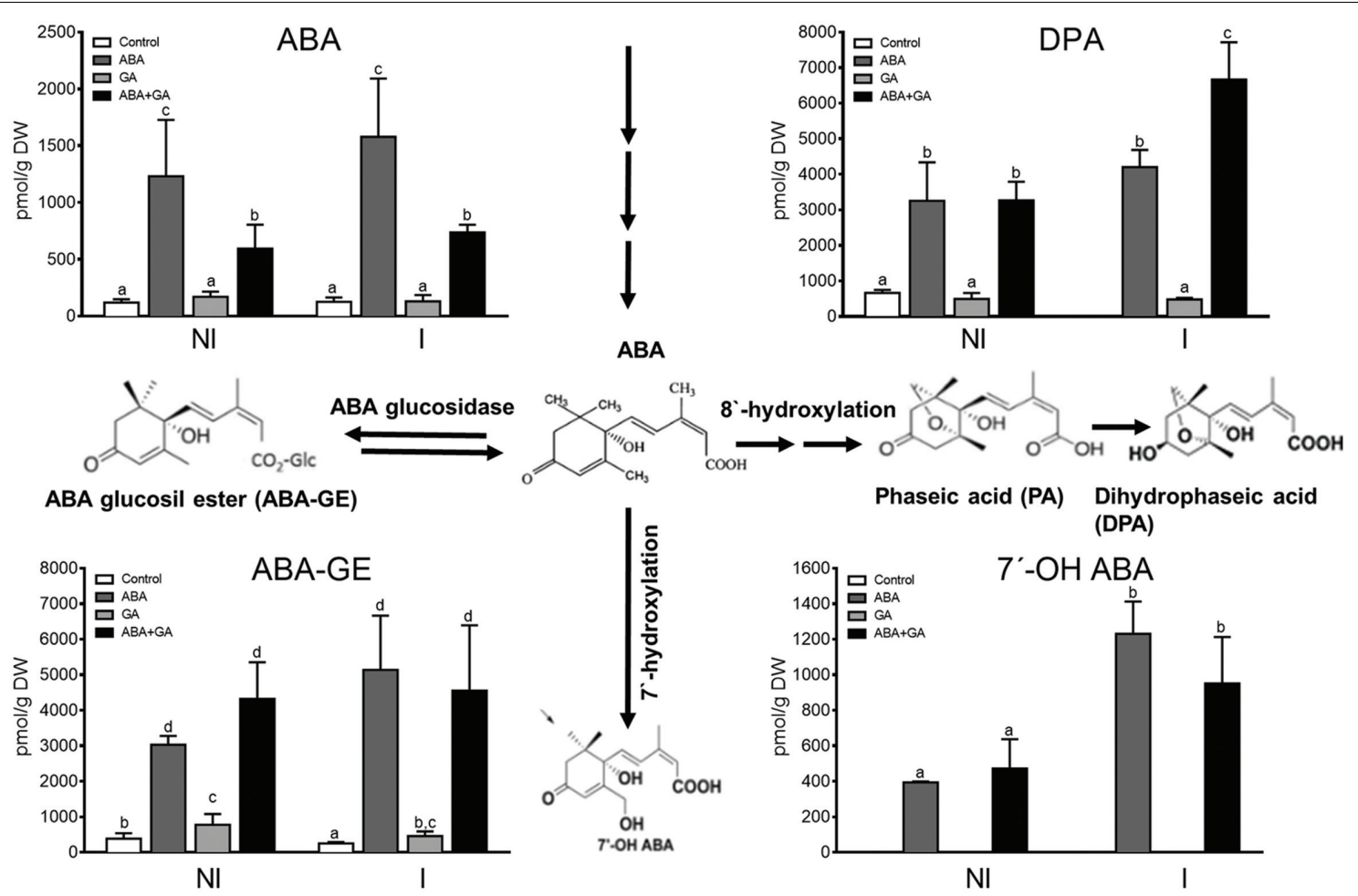

FIGURE 6 | Effect of ABA and $\mathrm{GA}_{3}$ applications on ABA metabolites contents in roots of Moneymaker tomato plants non-colonized (NI) or colonized with $\boldsymbol{R}$. irregularis (I). After 1 week of transplanting and inoculation with $R$. irregularis, a set of tomato plants (control) were treated with $0.1 \%$ ethanol solution, and three sets of plants were treated with $\mathrm{ABA}, \mathrm{GA}_{3}$, and $\mathrm{GA}_{3}+\mathrm{ABA}$. GA3 $(5 \mu \mathrm{M})$ and $\mathrm{ABA}(75 \mu \mathrm{M})$ solutions were applied to soil twice per week, and plants were harvested 50 days after inoculation. Products for ABA hydroxylation and ABA glycoxidation are shown. Values correspond to mean $\pm \mathrm{SE}(n=3)$, and bars with the same letter are not significantly different $(P=0.05)$ according to Duncan's multiple range test.

functionality, reached maximum levels in $\mathrm{ABA}$ and $\mathrm{ABA}+\mathrm{GA}_{3}$ treated plants (Figure 7C). Since SlPT4 reflects active arbuscules in tomato cells, arbuscule abundance (\%a and \%A) closely correlated with SIPT4 gene expression measurement data $\left(r^{2}=0.95\right)$.

We also studied the effects on mycorrhizal recovery in sitiens plants due to the application of $\mathrm{PrCa}$, a GA biosynthesis blocker. There was a major change in the mycorrhization parameters of the sitiens mutant when the PrCa was applied. In non-treated sitiens plants, the majority of arbuscules were in class A (near $50 \%$ ) with only $20 \%$ in class C. In sitiens plants treated with $\mathrm{PrCa}$, the majority of arbuscules were in class C (50\%) with only $20 \%$ in class A (Figure 8). With respect to plants treated with PrCa plus $\mathrm{GA}_{3}$, the three classes of arbuscules were present in similar proportions ( $30 \%$ for class A to $35 \%$ for class B). According to these changes in arbuscule morphology, PrCa treatment increased arbuscule abundance in mycorrhizal root fragments (\% a) as well as SIPT4 gene expression. The application of GAs together with PrCa counteracted the increase in \%a and SIPT4 gene expression caused by $\mathrm{PrCa}$ (Figure 8).

As data showed, the effect on mycorrhization of ABA applications in tomato sitiens plants is similar to the inhibition of GA biosynthesis by $\mathrm{PrCa}$ applications. In these ABAdeficient tomato plants, the independent application of both ABA and PrCa increased arbuscule abundance and abundance in mycorrhized roots ( $\% \mathrm{a}$ and $\% \mathrm{~A}$ ). This would indicate that there is a dependent and antagonistic relationship between $\mathrm{ABA}$ and GAs during AM development, although we cannot exclude that they could achieve a similar phenotype by acting independently. However, the fact that the application of $\mathrm{GA}_{3}$ attenuates these positive effects, suggest that the impairment of arbuscule formation by ABA deficiency is attributable to an ABA/GA imbalance in roots. Our findings on arbuscule morphology and mycorrhiza-related gene expression in sitiens plants treated with different compounds confirm that both ABA and PrCa have a similar positive impact on arbuscular formation in the mycorrhizal roots of ABA-deficient plants. As SIPT4 reflects plant activity in arbuscular cells, a close linear correlation exists between arbuscule abundance in mycorrhizal roots (\%A), the percentage of arbuscules with many branches as well as the high intensity of trypan blue stain and SIPT4 gene expression measurements.

As for wild-type plants, the GA pathway was clearly altered in sitiens plants after the application of ABA. This alteration was selective and mostly affected the 13-hydroxylation pathway (Supplementary Figure S4), decreasing the levels of bioactive $\mathrm{GA}_{1}$ and its precursor $\mathrm{GA}_{20}$ while those of $\mathrm{GA}_{6}$ catabolite increased (Supplementary Figure S4). Some crossover effects were detected when $\mathrm{ABA}$ and $\mathrm{GA}_{3}$ were applied jointly. The combined application of both compounds increases the 
A
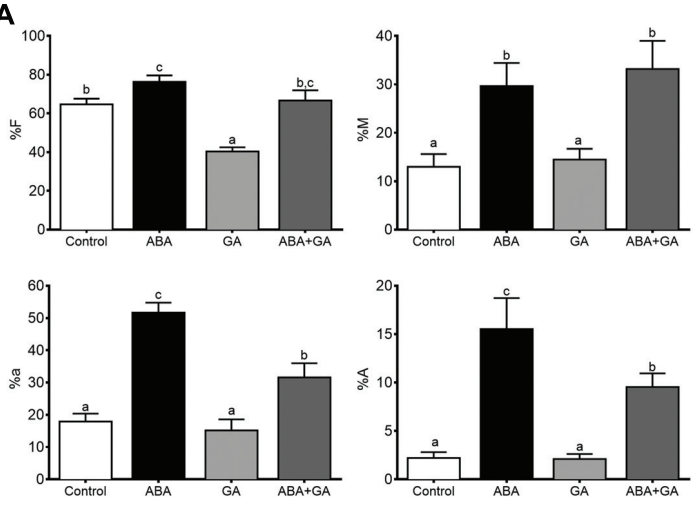

Mycorrhizal parameters

C

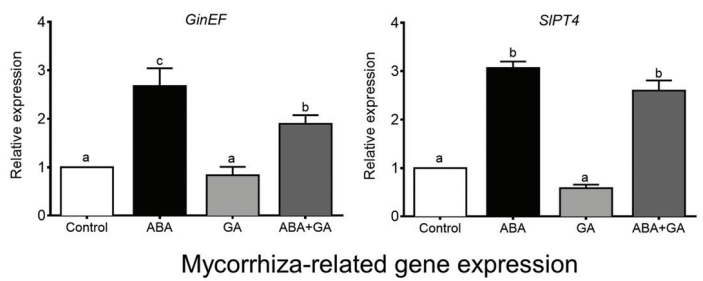

B
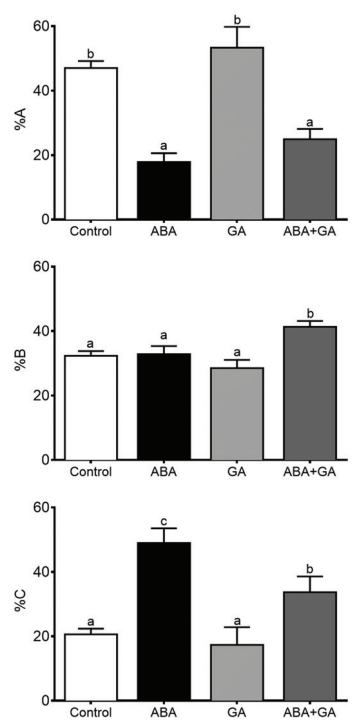

Morphological classes of arbuscules

FIGURE 7 | Effect of $\mathrm{ABA}$ and $\mathrm{GA}_{3}$ applications on mycorrhizal parameters (A), arbuscule distribution according to the different morphological classes $(B)$ and mycorrhizal related gene expression $(\mathbf{C})$ in roots of sitiens tomato plants colonized with $\boldsymbol{R}$. irregularis. After 1 week of transplanting and inoculation with $R$. irregularis, a set of sitiens tomato plants (control) were treated with $0.1 \%$ ethanol solution, and three sets of plants were treated with $A B A$, GA 3 , and $\mathrm{GA}_{3}+\mathrm{ABA} . \mathrm{GA}_{3}(5 \mu \mathrm{M})$ and $\mathrm{ABA}(75 \mu \mathrm{M})$ solutions were applied to soil twice per week, and plants were harvested 50 days after inoculation. qPCR data represents the expression of target genes in treated plants with respect to the expression in non-treated control plants in which expression was designated as 1. Values correspond to mean \pm SE $(n=3)$. Bars with same letters do not significantly differ $(P=0.05)$ according to Duncan's multiple range test.

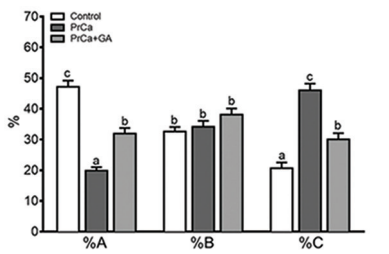

Morphological classes of arbuscules

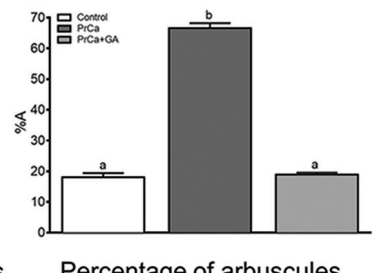

Percentage of arbuscules

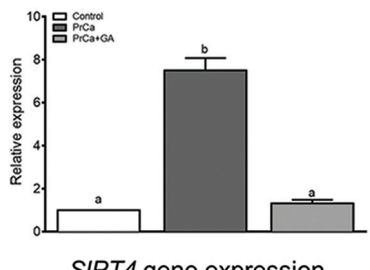

SIPT4 gene expression

FIGURE 8 | Effect of PrCa and $\mathrm{GA}_{3}$ applications on arbuscular distribution according to the different morphological classes, arbuscule abundance in the whole root system $(\% \mathrm{~A})$ and SIPT4 gene expression in roots of sitiens tomato plants colonized with $R$. irregularis. After 1 week of transplanting and inoculation with $R$. irregularis, a set of sitiens tomato plants (control) were treated with $0.1 \%$ ethanol solution, and three sets of plants were treated with $A B A$, GA 3 , and $\mathrm{GA}_{3}+\mathrm{ABA} . \mathrm{GA}_{3}(5 \mu \mathrm{M})$ and $\mathrm{ABA}(75 \mu \mathrm{M})$ solutions were applied to soil twice per week, and plants were harvested 50 days after inoculation. qPCR data represents the expression of target gene in treated plants with respect to the expression in non-treated control plants in which expression was designated as 1. Values correspond to mean $\pm \mathrm{SE}(n=3)$. Bars with same letters do not significantly differ $(P=0.05)$ according to Duncan's multiple range test.

concentration of $\mathrm{GA}_{15}$ catabolite and $\mathrm{GA}_{3}$ when applied together with $\mathrm{ABA}$ rescue the negative effect of $\mathrm{ABA}$ applications on $\mathrm{GA}_{9}$ accumulation. The application of $\mathrm{GA}_{3}$ in combination with $A B A$ rescued the negative effect on $G_{1}$ content caused by $\mathrm{ABA}$. Conversely, the application of $\mathrm{ABA}$ caused an increase in $\mathrm{GA}_{6}$ and $\mathrm{GA}_{29}$ compounds, which was eliminated in the presence of $\mathrm{GA}_{3}$. The application of $\mathrm{ABA}$ reduced $\mathrm{GA}_{20}$ content in sitiens roots, although there was no recovery in $\mathrm{GA}_{20}$ content when ABA was applied together with $\mathrm{GA}_{3}$. ABA applied alone or in combination with $\mathrm{GA}_{3}$ had a significant positive effect on the concentration of the $\mathrm{GA}_{13}$ metabolite
(Supplementary Figure S4). The increase in $\mathrm{GA}_{13}$ reflects the activation of an alternative pathway to non 13-hydroxylation and 13-hydroxylation pathways of GAs biosynthesis in the presence of ABA.

The expression patterns of selected genes from the GAbiosynthetic pathway (GA3ox1), from the GA-catabolic pathway $(G A 20 x 5)$ as well as GA signaling pathway (SIDELLA) were characterized. All three genes examined showed similar expression patterns characterized by a positive response to the application of ABA which was disabled by the presence of $\mathrm{GA}_{3}$ (Supplementary Figure S4). 
Summarizing, ABA increased DELLA transcript accumulation, induced GA catabolism and reduced bioactive $\mathrm{GA}_{1}$ concentrations in mycorrhizal sitiens roots. Altogether, these results suggest that exogenous ABA adversely affects the GA response. These alterations are dependent on the $\mathrm{ABA} / \mathrm{GA}$ balance in roots since the application of $\mathrm{GA}_{3}$ blocks the effects of ABA. Similarly, in Arabidopsis plants, it has been established that stabilization of DELLA by ABA treatments is achieved by reducing GA accumulation (Zentella et al., 2007). Some reports suggest that endogenous bioactive $G_{1}$ content significantly decreases with the application of $\mathrm{PrCa}$, as GA biosynthesis is interrupted at later stages when $\mathrm{GA}_{20}$ is converted to $\mathrm{GA}_{1}$ (Kim et al., 2007, 2010; Kang et al., 2010). When sitiens plants were treated with exogenous ABA, the ABA content increased more than 10 -fold in roots. Nevertheless, endogenous $A B A$ remained at a low level following $A B A+G_{3}$ applications, suggesting once again that the presence of $\mathrm{GA}_{3}$ prevents accumulation in the roots of the exogenous free ABA applied.

\section{CONCLUSION}

Arbuscule formation requires the presence of DELLA proteins and GAs negatively regulate their formation through DELLA degradation (Floss et al., 2013; Foo et al., 2013; Yu et al., 2014; Pimprikar et al., 2016). Therefore, the control of GA levels through a combination of biosynthesis and degradation provides a mechanism for regulating and fine-tuning GA levels in mycorrhizal roots (Martín-Rodríguez et al., 2015; this study) and consequently arbuscules formation. Our findings highlight a link between ABA and GAs that regulates arbuscule formation, and some of the data obtained support the hypothesis that ABA may act in part via modifying GA level to regulate AM. Accordingly, the ABA/GA hormonal balance could be regarded as an important mechanism in the regulation of symbiosis. Taken as a whole, these observations suggest that, apart from the individual role played by each of these hormones, they also perform essential overlapping functions, indicating that these isoprenoid-derived plant hormones are at the core of the network for regulating AM symbiosis. Furthermore, there are reasons to postulate that an optimum hormonal balance of ABA/GAs is essential for the regulation of others hormones such as auxin,

\section{REFERENCES}

Achard, P., Cheng, H., Grauwe, L., Decat, J., Schoutteten, H., Moritz, T., et al. (2006). Integration of plant responses to environmentally activated phytohormonal signals. Science 311, 91-94. doi: 10.1126/science.1118642

Balestrini, R., Gómez-Ariza, J., Lanfranco, L., and Bonfante, P. (2007). Laser microdissection reveals that transcripts for five plant and one fungal phosphate transporter genes are contemporaneously present in arbusculared cells. Mol. Plant Microbe Interact. 20, 1055-1062. doi: 10.1094/MPMI-20-9-1055

Bassel, G. W., Mullen, R. T., and Bewley, J. D. (2008). Procera is a putative DELLA mutant in tomato (Solanum lycopersicum): effects on the seed and vegetative plant. J. Exp. Bot. 59, 585-593. doi: 10.1093/jxb/erm354

Bonfante, P., and Genre, A. (2010). Mechanisms underlying beneficial plantfungus interactions in mycorrhizal symbiosis. Nat. Commun. 1:48. doi: $10.1038 /$ ncomms 1046 cytokinins, strigolactone or ethylene whose participation on AM formation has also been reported recently (López-Ráez et al., 2010; Martín-Rodríguez et al., 2011; Etemadi et al., 2014; Cosme et al., 2016).

\section{AUTHOR CONTRIBUTIONS}

JG-G, JO, and JM-R conceived and designed the research; JM-R, $\mathrm{RH}$, and TH-P performed experiments; VT, DT, and JL-M performed $\mathrm{ABA}$ and GAs determinations and analyzed the data; JG-G draft the manuscript. All authors have read and approved the manuscript for publication.

\section{FUNDING}

This study was supported by grants from the Comision Interministerial de Ciencia y Tecnología (CICYT) and Fondos Europeos de Desarrollo Regional (FEDER) through the Ministerio de Economía y Competitividad in Spain (AGL200800742; AGL2011-25930) as well as the Junta de Andalucía (Research Group BIO 260). JM-R was supported by a research fellowship from the FPU-MICINN program. The work on hormone measurements was funded by a Grant Agency of the Czech Republic (grant no. 14-34792S) and by the Ministry of Education, Youth and Sports of the Czech Republic through the National Program for Sustainability I (Nr. LO1204).

\section{ACKNOWLEDGMENTS}

We wish to thank the TGRC of the University of California for providing tomato seeds. We would also like to thank Isabel Tamayo and Nuria Molinero for their help with the plant experiments and Michael O'Shea for proof-reading the document.

\section{SUPPLEMENTARY MATERIAL}

The Supplementary Material for this article can be found online at: http://journal.frontiersin.org/article/10.3389/fpls.2016.01273

Brown, R. G. S., Kawaide, H., Yang, Y. Y., and Kamiya, Y. (1997). Daminozide and prohexadione have similar modes of action as inhibitors of the late stages of gibberellin metabolism. Physiol. Plant 101, 309-313. doi: 10.1111/j.13993054.1997.tb01001.x

Chabot, C., Bécard, G., and Piché, Y. (1992). Life cycle of Glomus intraradix in root organ culture. Mycologia 84, 315-321. doi: 10.2307/376 0183

Charpentier, M., Sun, J., Wen, J., Mysore, K. S., and Oldroyd, G. (2014). ABA promotion of arbuscular mycorrhizal colonization requires a component of the PP2A protein phosphatase complex. Plant Physiol. 166, 2077-2090. doi: 10.1104/pp.114.246371

Chitarra, W., Pagliarani, C. H., Maserti, B., Lumini, E., Siciliano, I., Cascone, P., et al. (2016). Insights on the impact of arbuscular mycorrhizal symbiosis on tomato tolerance to water stress. Plant Physiol. 171, 1009-1023. doi: 10.1104/pp.16.00307 
Cosme, M., Ramireddy, E., Franken, P., Schmülling, T., and Wurst, S. (2016). Shoot- and root-borne cytokinin influences arbuscular mycorrhizal symbiosis. Mycorrhiza 1-12. doi: 10.1007/s00572-016-0706-3

El Ghachtouli, N., Martin-Tanguy, J., Paynot, M., and Gianinazzi, S. (1996). First report of the inhibition of arbuscular mycorrhizal infection of Pisum sativum by specific and irreversible inhibition of polyamine biosynthesis or by gibberellic acid treatment. FEBS Lett. 385, 189-192. doi: 10.1016/0014-5793(96) 00379-1

Etemadi, M., Gutjahr, C., Couzigou, J.-M., Zouine, M., Lauressergues, D., Timmers, A., et al. (2014). Auxin perception is required for arbuscule development in arbuscular mycorrhizal symbiosis. Plant Physiol. 166, 281-292. doi: $10.1104 /$ pp. 114.246595

Fiorilli, V., Catoni, M., Miozzi, L., Novero, M., Accotto, G. P., and Lanfranco, L. (2009). Global and cell-type gene expression profiles in tomato plants colonized by an arbuscular mycorrhizal fungus. New Phytol. 184, 975-987. doi: 10.1111/j.1469-8137.2009.03031.x

Floss, D., Levy, J., Lévesque-Tremblay, V., Pumplin, N., and Harrison, M. (2013). DELLA proteins regulate arbuscule formation in arbuscular mycorrhizal symbiosis. Proc. Natl. Acad. Sci. U. S. A. 110, E5025-E5034. doi: 10.1073/pnas.1308973110

Foo, E., Rossi, J. J., Jones, W. T., and Reid, J. B. (2013). Plant hormones in arbuscular mycorrhizal symbioses: an emerging role for gibberellins. Ann. Bot. 111, 769-779. doi: 10.1093/aob/mct041

García-Garrido, J. M., León-Morcillo, R. J., Martín-Rodríguez, J. A., and Ocampo-Bote, J. A. (2010). Variations in the mycorrhization characteristics in roots of wild-type and ABA-deficient tomato are accompanied by specific transcriptomic alterations. Mol. Plant Microbe Interact. 23, 651-664. doi: 10.1094/MPMI-23-5-0651

Gonai, T., Kawahara, S., Tougou, M., Satoh, S., Hashiba, T., Hirai, N., et al. (2004). Abscisic acid in the thermoinhibition of lettuce seed germination and enhancement of its catabolism by gibberellin. J. Exp. Bot. 55, 111-118. doi: $10.1093 / \mathrm{jxb} / \mathrm{erh} 023$

Gutjahr, C. (2014). Phytohormone signaling in arbuscular mycorrhiza development. Curr. Opin. Plant Biol. 20, 26-34. doi: 10.1016/j.pbi.2014. 04.003

Hedden, P., and Thomas, G. (2012). Gibberellin biosynthesis and its regulation. Biochem. J. 444, 11-25. doi: 10.1042/BJ20120245

Herrera-Medina, M. J., Steinkellner, S., Vierheilig, H., Ocampo Bote, J. A., and García-Garrido, J. M. (2007). Abscisic acid determines arbuscule development and functionality in the tomato arbuscular mycorrhiza. New Phytol. 175, 554564. doi: 10.1111/j.1469-8137.2007.02107.x

Hewitt, E. J. (1966). Sand Water Culture Methods Used in the Study of Plant Nutrition. Technical Communication 22. Farnham Royal: Commonwealth Agricultural Bureaux..

Hradecká, V., Novák, O., Havlíček, L., and Strnad, M. (2007). Immunoaffinity chromatography of abscisic acid combined with electrospray liquid chromatography-mass spectrometry. J. Chromatogr. B 847, 162-173. doi: 10.1016/j.jchromb.2006.09.034

Kang, S. M., Kim, J. T., Hamayun, M., Hwang, I. C., Khan, A. L., Kim, Y. H., et al. (2010). Influence of prohexadione-calcium on growth and gibberellins content of Chinese cabbage grown in alpine region of South Korea. Sci. Hort. 125, 88-92. doi: 10.1016/j.scienta.2010.02.018

Kim, H. Y., Lee, I. J., Hamayun, M., Kim, J. T., Won, J. G., Hwang, I. C., et al. (2007). Effect of prohexadione calcium on growth components and endogenous gibberellins contents of rice (Oryza sativa L.). J. Agron. Crop Sci. 193, 445-451. doi: 10.1111/j.1439-037X.2007.00280.x

Kim, Y. H., Khan, A. L., Hamayun, M., Kim, J. T., Lee, J. H., Hwang, I. C., et al. (2010). Effects of prohexadione calcium on growth and gibberellins contents of Chrysanthemum morifolium R. cv Monalisa White. Sci. Hort. 123, 423-427. doi: 10.1016/j.scienta.2009.09.022

Kucera, B., Cohn, M. A., and Leubner-Metzger, G. (2005). Plant hormone interactions during seed dormancy release and germination. Seed Sci. Res. 15, 281-307. doi: 10.1079/SSR2005218

Kushiro, T., Okamoto, M., Nakabayashi, K., Yamagishi, K., Kitamura, S., Asami, T., et al. (2004). The Arabidopsis cytochrome P450 CYP707A encodes ABA 8hydroxylases: key enzymes in ABA catabolism. EMBO J. 23, 1647-1656. doi: 10.1038/sj.emboj.7600121
Lee, K. H., Piao, H. L., Kim, H. Y., Choi, S. M., Jiang, F., Hartung, W., et al. (2006). Activation of glucosidase via stress-induced polymerization rapidly increases active pools of abscisic acid. Cell 126, 1109-1120. doi: 10.1016/j.cell.2006.07.034

Livak, K. J., and Schmittgen, T. D. (2001). Analysis of relative gene expression data using real-time quantitative PCR and the 2(-Delta Delta C(T)) Method. Methods 25, 402-408. doi: 10.1006/meth.2001.1262

López-Ráez, J. A., Kohlen, W., Charnikhova, T., Mulder, P., Undas, A. K., Sergeant, M. J., et al. (2010). Does abscisic acid affect strigolactone biosynthesis? New Phytol. 187, 343-354. doi: 10.1111/j.1469-8137.2010.03291.x

Ludwig-Müller, J. (2010). "Hormonal responses in host plants triggered by arbuscular mycorrhizal fungi," in Arbuscular Mycorrhizas: Physiology and Function, eds H. Koltai and Y. Kapulnik (Springer: Science Business Media B.V), 169-190.

Mahouachi, J., Gómez-Cadenas, A., Primo-Millo, E., and Talon, M. (2005). Antagonistic changes between abscisic acid and gibberellins in citrus fruits subjected to a series of different water conditions. J. Plant Growth Regul. 24, 179-187. doi: 10.1007/s00344-004-0001-y

Martín-Rodríguez, J. A., León-Morcillo, R., Vierheilig, H., Ocampo Bote, J. A., Ludwig-Müllerm, J., García-Garrido, J. M., et al. (2010). Mycorrhization of the notabilis and sitiens tomato mutants in relation to abscisic acid and ethylene contents. J. Plant Physiol. 167, 606-613. doi: 10.1016/j.jplph.2009.11.014

Martín-Rodríguez, J. A., León-Morcillo, R. J., Vierheilig, H., Ocampo-Bote, J. A., Ludwig-Müller, J., and García-Garrido, J. M. (2011). Ethylenedependent/ethylene-independent ABA regulation of tomato plants colonized by arbuscular mycorrhiza fungi. New Phytol. 190, 193-205. doi: 10.1111/j.14698137.2010.03610.x

Martín-Rodríguez, J. A., Ocampo, J. A., Molinero-Rosales, N., Tarkowská, D., Ruíz-Rivero, O., and García-Garrido, J. M. (2015). Role of gibberellins during arbuscular mycorrhizal formation in tomato: new insights revealed by endogenous quantification and genetic analysis of their metabolism in mycorrhizal roots. Physiol. Plant 154, 66-81. doi: 10.1111/ppl.12274

Oh, E., Yamaguchi, S., Hu, J. H., Yusuke, J., Jung, B., Paik, I., et al. (2007). PIL5, a phytochrome-interacting bHLH protein, regulates gibberellin responsiveness by binding directly to the GAI and RGA promoters in Arabidopsis seeds. Plant Cell 19, 1192-1208. doi: 10.1105/tpc.107.050153

Phillips, J. M., and Hayman, D. S. (1970). Improved procedures for clearing roots and staining parasitic and vesicular-arbuscular mycorrhizal fungi for rapid assessment of infection. Trans. Br. Mycol. Soc. 55, 158-161. doi: 10.1016/S00071536(70)80110-3

Pimprikar, P., Carbonnel, S., Paries, M., Katzer, K., Klingl, V., Bohmer, M. J., et al. (2016). A CCaMK-CYCLOPS-DELLA complex activates transciption of RAM1 to regulate arbuscule branching. Curr. Biol. 26, 1-12. doi: 10.1016/j.cub.2016.01.069

Pozo, M. J., López-Ráez, J. A., Azcón, C., and García-Garrido, J. M. (2015). Phytohormones as integrators of environmental signals in the regulation of mycorrhizal symbioses. New Phytol. 205, 1431-1436. doi: 10.1111/nph.13252

Rittenberg, D., and Foster, G. L. (1940). New procedure for quantitative analysis by isotope dilution, with application to the determination of amino acids and fatty acids. J. Biol. Chem. 133, 737-744.

Rodríguez-Gacio, M., Matilla-Vázquez, M. A., and Matilla, A. J. (2009). Seed dormancy and ABA signaling. Plant Signal. Behav. 4, 1035-1048. doi: 10.4161/psb.4.11.9902

Ruiz-Lozano, J. M., Aroca, R., Zamarreño, A. M., Molina, S., Andreo-Jiménez, B., Porcel, R., et al. (2016). Arbuscular mycorrhizal symbiosis induces strigolactone biosynthesis under drought and improves drought tolerance in lettuce and tomato. Plant Cell Environ. 39, 441-452. doi: 10.1111/pce.1263

Schüßler, A., and Walker, C. (2010). The Glomeromycota. A Species List With New Families and New Genera. Edinburgh: The Royal Botanic Garden.

Seo, M., Hanada, A., Kuwahara, A., Endo, A., Okamoto, M., Yamauchi, Y., et al. (2006). Regulation of hormone metabolism in Arabidopsis seeds: phytochrome regulation of abscisic acid metabolism and abscisic acid regulation of gibberellin metabolism. Plant J. 48, 354-366. doi: 10.1111/j.1365-313X.2006. 02881.x

Shaul-Keinan, O., Gadkar, V., Ginzberg, I., Grünzweig, J. M., Chet, I., Elad, Y., et al. (2002). Hormone concentrations in tobacco roots change during arbuscular mycorrhizal colonization with Glomus intraradices. New Phytol. 154, 501-507. doi: 10.1046/j.1469-8137.2002.00388.x 
Shu, K., Chen, Q., Wu, Y., Liu, R., Zhang, H., Wang, P., et al. (2016). ABI4 mediates antagonistic effects of abscisic acid and gibberellins at transcript and protein levels. Plant J. 85, 348-361. doi: 10.1111/tpj.13109

Silverstone, A., Jung, H.-S., Dill, A., Kawaide, H., Kamiya, Y., and Sun, T. (2001). Repressing a repressor: gibberellin-induced rapid reduction of the RGA protein in Arabidopsis. Plant Cell 13, 1555-1565. doi: 10.1105/TPC.010047

Smith, S. E., and Read, D. J. (2008). Mycorrhizal Symbiosis. London: Academic Press.

Taylor, I. B., Linforth, R. S. T., Al Naieb, R. J., Bowman, W. R., and Marples, B. A. (1988). The wilty tomato mutants flacca and sitiens are impaired in the oxidation of ABA-aldehyde to ABA. Plant Cell Environ. 11, 739-745. doi: 10.1111/j.1365-3040.1988.tb01158.x

Trouvelot, A., Kough, J. L., and Gianinazzi-Pearson, V. (1986). "Mesure du taux de mycorrhization VA d'un système radiculaire. Recherche de methods d'estimation ayant une signification fonctionelle," in Physiological and Genetical Aspects of Mycorrhizae, eds V. Gianinazzi-Pearson and S. Gianinazzi (France: INRA Paris), 217-221.

Turečková, V., Novák, O., and Strnad, M. (2009). Profiling ABA metabolites in Nicotiana tabacum L. leaves by ultra-performance liquid chromatographyelectrospray tandem mass spectrometry. Talanta 80, 390-399. doi: 10.1016/j.talanta.2009.06.027

Urbanová, T., Tarkowská, D., Novák, O., Hedden, P., and Strnad, M. (2013). Analysis of gibberellins as free acids by ultra-performance liquid chromatography-tandem mass spectrometry. Talanta 112, 85-94. doi: 10.1016/j.talanta.2013.03.068

Van Tuinen, A., Peters A. H. L. J., Kendrick, R. E., Zeevaart, J.A.D., and Koornneef, M. (1999). Characterisation of the procera mutant of tomato and the interaction of gibberellins with end-of-day far-red light treatments. Physiol. Plant 106, 121-128. doi: 10.1034/j.1399-3054.1999.106117.x

Weiss, D., and Ori, N. (2007). Mechanisms of cross talk between gibberellin and other hormones. Plant Physiol. 144, 1240-1246. doi: 10.1104/pp.107.100370

White, C. N., Proebsting, W. M., Hedden, P., and Rivin, C. J. (2000). Gibberellins and seed development in maize. I. Evidence that gibberellin/abscisic acid balance governs germination versus maturation pathways. Plant Physiol 122, 1081-1088. doi: 10.1104/pp.122.4.1081

Yu, N., Luo, D., Zhang, X., Liu, J., Wang, W., Jin, Y., et al. (2014). A DELLA protein complex controls the arbuscular mycorrhizal symbiosis in plants. Cell Res. 24, 130-133. doi: 10.1038/cr.2013.167

Zentella, R., Zhang, Z. L., Park, M., Thomas, S. G., Endo, A., Murase, K., et al. (2007). Global analysis of DELLA direct targets in early gibberellin signaling in Arabidopsis. Plant Cell 19, 3037-3057. doi: 10.1105/tpc.107. 054999

Conflict of Interest Statement: The authors declare that the research was conducted in the absence of any commercial or financial relationships that could be construed as a potential conflict of interest.

Copyright (C) 2016 Martín-Rodríguez, Huertas, Ho-Plágaro, Ocampo, Turečková, Tarkowská, Ludwig-Müller and García-Garrido. This is an open-access article distributed under the terms of the Creative Commons Attribution License (CC BY). The use, distribution or reproduction in other forums is permitted, provided the original author(s) or licensor are credited and that the original publication in this journal is cited, in accordance with accepted academic practice. No use, distribution or reproduction is permitted which does not comply with these terms. 